\title{
Ontologia Ambiental: o reposicionamento do Ser no horizonte da Racionalidade Ambiental
}

\section{Environmental Ontology: repositioning of Being on the horizon of Environmental Rationality}

\author{
Thais de Oliveira Nabaes ${ }^{1}$ \\ Vilmar Alves Pereira ${ }^{2}$
}

\begin{abstract}
RESUMO
A presente discussão é oriunda de uma tese de doutorado em Educação Ambiental que se propôs a discutir o Ser sob duas perspectivas: a da Racionalidade Instrumental e a da Racionalidade Ambiental. Questionando em que medida o horizonte da Racionalidade Ambiental poderia contribuir para (re)significar e situar o Ser, empreendemos um exercício hermenêutico, a fim de alargar a compreensão de categorias postas para o estudo. Tomando como uma das referências possíveis a perspectiva teórica de Enrique Leff, apresentamos alternativas para pensar o Ser no horizonte de uma nova Racionalidade, considerando que esta além de superar as patologias da Razão Instrumental pode constituir-se em um novo indicador para nosso modo de ser-no-mundo.
\end{abstract}

Palavras-chave: Educação Ambiental; Ser; Racionalidade Ambiental.

\footnotetext{
ABSTRACT

This discussion is part of a thesis in Environmental Education, which proposed to discuss Being in two perspectives: the Instrumental Rationality

DOI: $10.1590 / 0104-4060.45961$

1 Instituto Federal de Educação, Ciência e Tecnologia do Rio Grande do Sul. Rio Grande, Rio Grande do Sul, Brasil. Campus Rio Grande. Rua Engenheiro Alfredo Huch, n ${ }^{\circ} 475$. Vila Santa Tereza. CEP: 96.201-460.E-mail: nabaes.prof@gmail.com

2 Universidade Federal do Rio Grande. Pró-Reitoria de Assuntos Estudantis. Rio Grande, Rio Grande do Sul, Brasil. Campus Carreiros. Av. Itália Km 8. Bairro Carreiros. CEP: 96.201-900. E-mail: vilmar1972@gmail.com
} 
and the Environmental Rationality. Asking about how the Environmental Rationality view could contribute to (re)define and situate Being, we did a hermeneutical exercise in order to broaden understanding of categories put to the study. Taking as a possible reference the theoretical perspective of Enrique Leff, we present alternatives to think Being on the horizon of a new Rationality, considering that, in addition to overcoming the pathologies of Instrumental Reason, it may be up in a new perspective to our way-ofbeing in the world.

Keywords: Environmental Education; Being; Environmental Rationality.

\section{Introdução}

A forma ocidental de pensarmos o mundo produziu patologias nas sociedades hodiernas. $\mathrm{O}$ individualismo exacerbado, as diferentes formas de domínio, as indiferenças, a aparente onipotência do sistema capitalista e os desvios da Razão expressam entendimentos particulares de sujeito e denunciam uma crise nos fundamentos da Racionalidade Moderna. Em nossa compreensão, ao buscar compreender esses fenômenos, a Educação Ambiental discute a necessidade de reconstrução de nossas relações sobre o legado de outra Racionalidade, que subverta o logocentrismo das Ciências Modernas e seja capaz de abrir novas perspectivas para a promoção da vida.

A pretensão de implantar uma nova ordem no mundo sob o domínio da Razão mostrou-se um projeto fracassado. O aumento das desigualdades, as guerras e as demais mazelas sociais, a depredação do ambiente natural e as diferentes formas de subjugação mantiveram a humanidade presa à condição de escravidão. Do Mito ao Iluminismo, as concepções de Ser estiveram marcadas pela ideia de domínio, fosse ele sobre a natureza ou como pano de fundo das relações sociais. Segundo nossa compreensão, o sentido de Ser nas sociedades contemporâneas está permeado por uma Racionalidade que se tornou reducionista, ao colocar a humanidade fora da natureza, instaurando a mais radical e generalizada alienação. (MÜHL, 1996).

Somado a isso, o fato de nas sociedades modernas o conceito de Racionalidade ter se tornado uma espécie de bandeira para o "progresso" e uma amarra para a ressignificação do próprio conhecimento humano (criando verdadeiros dogmas científico-filosóficos), levou-nos a uma crise ambiental que, em seu bojo, é uma crise do pensamento ocidental.

Apresentamos neste texto um recorte de uma tese de doutorado que investigou, a partir de um exercício hermenêutico, em que medida o horizonte da 
Racionalidade Ambiental poderia contribuir para (re)significar e situar o Ser. No estudo original apontamos que a tentativa de explicar em que consiste este $\mathrm{Ser}$ da Humanidade, assumiu na História da Filosofia diferentes percursos epistemológicos. De forma muito ampla, pode-se destacar que por vezes a discussão metafísica esteve ligada a elementos da natureza (primeiros filósofos); polarizada, como em Parmênides (o Ser é, o Não Ser não é); associada ao movimento (Heráclito); marcada pela ascese ao ideal (Platão); demarcada em categorias (Aristóteles); identificada com as questões teológicas (no Medievo); para, a seguir, ser destituída de elementos religiosos e centralizada no sujeito (Modernidade).

Se a partir dos séculos XVIII e XIX a concepção de Ser esteve relacionada com aspectos de propriedade (como em Locke e Rousseau, por exemplo), no período pós-industrial a Racionalidade Instrumental se sobrepujou como orientadora das formas de ser-no-mundo. A partir desta ótica, percebemos a existência de outro tipo de construção ontológica, que se mostra predominante na sociedade capitalista: o Ter como base para estruturação do Ser e para os contratos sociais.

Entendemos que a abordagem hermenêutica, enquanto método e epistemologia, nos permitiu alargar a compreensão do tema, favorecendo o diálogo com os pressupostos da Racionalidade Ambiental, e empreender uma movimentação em direção a outros sentidos para a compreensão do Ser, que divergem da leitura que tem sido feita pela Racionalidade Ocidental Moderna.

\section{A compreensão do saber ambiental e o reposicionamento da razão}

Ao alargar a compreensão de Racionalidade para além da consecução de objetivos civilizatórios ou econômicos, a Racionalidade Ambiental se lança à tarefa de desconstruir a visão logocêntrica, questionando o conhecimento que temos sobre o mundo e, sobretudo, a "[...] vontade homogeneizante da unidade da ciência e a unificação forçada do mercado". (PORTO-GONÇALVES, 2006, p. 15). A Racionalidade Ambiental emerge do questionamento dos excessos do pensamento objetificador e utilitarista, que conduziu à coisificação do Ser e à superexploração da natureza. Ao mostrarem-se fora da ordem puramente simbólica, as leis-limite da natureza deflagraram uma crise que ameaça a integridade da vida em seus diferentes aspectos/sistemas.

Para Leff, o colapso ecológico incitou um novo olhar sobre a dialética da natureza e a dialética da história. Dos primeiros gregos ao formalismo mecanicista de Descartes, até o conceito marxista de natureza, não há a reivin- 
dicação de uma "ontologia simétrica". (STEIL; CARVALHO, 2014, p. 166). A representação do real tende a ser antropocêntrica, pois parte daquele que diz e interpreta o mundo - o ser humano. Steil e Carvalho (2014, p. 163) defendem que "[...] nosso modo de habitar o planeta não está separado de nosso modo de conhecê-lo". É por isso que o saber ambiental pode constituir-se em um "[...] questionamento do pensamento metafísico que reduziu o mundo a entes a e a natureza a coisas". (LEFF, 2006a, p. 66), pois ao considerar o ambiente como categoria sociológica, confronta Racionalidades e tradições abrindo "uma relação escatológica com o Ser e com a história”. (LEFF, 2006a, p. 175).

$\mathrm{Na}$ Racionalidade Ambiental discute-se a necessidade de pensar a vida a partir de outras categorias. A questão da Outridade, tomada a partir de Levinas, inscreve-se na perspectiva de romper com o individualismo e a indiferença, desenvolvendo um sentido de responsabilidade pelo Outro, que é aquele que está para além do Eu. O pensamento ocidental se constituiu em totalidade ao tentar neutralizar as diferenças, abarcando com o discurso toda a possibilidade de manifestação da existência. Além disso, a complexidade ambiental ${ }^{3}$ coloca em discussão a emergência de categorias de pensamento adicionais, como a Identidade e a Diferença. Neste contexto, a Identidade coloca-se como posicionamento no mundo (individual e coletivo), daí advém a necessidade de uma construção social do saber, enraizada nos diferentes modos de Ser, nos potenciais da natureza e nos sentidos da cultura. O Ser, desta maneira, se construiria no tempo, no lugar, na coletividade e na convivência. Leff defende que a construção do indivíduo se dá no encontro com o Outro. Neste sentido, afirma que

A pedagogia da complexidade ambiental é aprender um saber ser com a outridade, que vai mais além do "conhece-te a ti mesmo", como a arte da vida. O saber ambiental integra o conhecimento do limite e o sentido da existência. [...]. É um ser que se constitui na incompletude do conhecimento e na pulsão do saber. (LEFF, 2006a, p. 221).

Assim, o conceito de saber ambiental incorpora princípios éticos e valores culturais, emergindo do questionamento de tudo que se mostra insustentável

3 Leff discute o pensamento complexo, assim como "interpela" o racionalismo crítico, o estruturalismo, a filosofia epistêmica de Foucault, a economia política de Marx e a racionalidade na perspectiva de Weber. O pensamento complexo pretende lançar uma visão interdisciplinar acerca dos sistemas e instâncias da realidade, questionando todas as formas de pensamento unilateral, dogmático e instrumental. Trabalha com o paradoxo do uno e do múltiplo, recorrendo a uma abordagem multirreferenciada e multidisciplinar para a construção do conhecimento. Tem como alguns de seus expoentes Edgar Morin e Ilya Prigogine. 
para a vida - tanto material como simbólica. A complexidade ambiental não consiste na ecologização do mundo, nem na dissolução das especificidades das ciências, mas na compreensão de que a ciência, os regimes sociais, os modos de produção, as organizações sociais são formas de dizer e produzir o real que também habitam o "mundo impermanente e instável das coisas". (STEIL; CARVALHO 2014, p. 172). Ou seja, são possibilidades de interpretar e viver o mundo em que habitamos. Não são as únicas vias. Este reposicionamento da razão, da vida e das relações impele-nos a outras formas de compreender o Ser na contemporaneidade.

\section{A Racionalidade Ambiental e o reposicionamento do Ser}

Leff entende que as sociedades modernas - tanto as capitalistas como as socialistas - seriam produtivistas e antiecológicas. Devido a isto, seria necessária a busca de uma estratégia produtiva alternativa, com a reapropriação social da natureza acontecendo a partir da gestão direta e compartilhada dos recursos naturais, por exemplo.

Em nosso entendimento, para efetivação de uma nova Racionalidade, torna-se necessária a incorporação do saber ambiental no campo das chamadas ciências tradicionais a fim de que se faça uma análise integrada da realidade, mobilizando e articulando um "[...] conjunto de saberes técnicos e práticos, associados ao reconhecimento, valorização e formas de uso dos recursos naturais". (LEFF, 2006a, p. 86).

Toda estratégia teórica orientada para os processos ambientais está vinculada a uma prática social, ecológica ou tecnológica e é por isso que a ideia de Racionalidade Ambiental não é a simples expressão de uma lógica particular, mas " [...] o efeito de um conjunto de práticas sociais e culturais diversas e heterogêneas, que dão sentido e organizam os processos sociais [...] [e] ultrapassam as leis derivadas da estrutura de um modo de produção". (LEFF, 2006a, p. 125).

Compreende-se que as Racionalidades são fundadas a partir de determinadas premissas e também produzem (e reproduzem) o "espírito de uma época". Projetar o Ser no horizonte de outra Racionalidade nos leva a pensar sobre formas de consciência e sua concretude nas esferas de vida pública e privada. Neste sentido, a Racionalidade Ambiental assume uma dimensão ontológica, que pressupõe uma mudança no entendimento da Razão e de nossas formas de ser-no-mundo. Se o conceito de Racionalidade ainda está associado à condução "racional" do pensamento na consecução de objetivos de controle da realida- 
de, na contramão deste pensamento pode se inscrever a Educação Ambiental, ultrapassando a "sensibilidade ecológica" ao converter-se num projeto político de promoção da vida. Ou seja, empreendendo um esforço para transformar os valores sobre os quais se alicerçam as sociedades modernas, problematizando as relações que temos construído.

Ao fazermos uma leitura da História da Metafísica Ocidental, vemos que Parmênides foi o primeiro pensador grego que pode ser apropriadamente chamado de metafísico, pois coloca a questão do Ser como objeto primordial da reflexão filosófica. Parmênides opõe Ser e Não Ser, produzindo um discurso que ressalta a identidade e perenidade do primeiro. Já Heráclito foi consagrado pela doxografia como o filósofo do devir e, ao defender a doutrina do fluxo universal, avança nas reflexões dos demais pré-socráticos justamente por formular o problema da unidade permanente do Ser diante da pluralidade e transitoriedade do mundo.

A seguir, vemos que da dedicação de Platão à resolução do impasse filosófico entre Heráclito e Parmênides (a antítese entre o fluir perene e a imutabilidade) houve a construção de uma perspectiva metafísica nova: a proposição da existência de uma dimensão suprafísica do Ser. Se Platão tenta resolver o impasse dos pré-socráticos situando o Ser na esfera do inteligível, Aristóteles revaloriza a dimensão do sensível. Segundo seu entendimento, as essências das coisas materiais estão nelas mesmas. Não haveria, como em Platão, diferentes graus de Ser, mas diferentes modos do Ser manifestar-se (daí a Teoria Hilemórfica, a Teoria das Causas e a Doutrina do Ato e Potência, por exemplo).

Já no Medievo, o logos filosófico encontra-se atrelado à Teologia. O tomismo é erigido como edifício metafísico fundamental no seio da doutrina cristã. A partir de então, o mundo é entendido na perspectiva de contingência, sendo Deus o único Ser Necessário. Com a decadência dos paradigmas do mundo medieval, entra em questão outro horizonte: o da Subjetividade, firmado na Era Moderna. O Ser deixa de ser tratado como abstração. Se na Idade Média o homem era sinônimo de sua alma, na Modernidade este ser/humanidade torna-se sinônimo de sujeito, aquele capaz de dar sentido à realidade.

A aproximação feita em nosso estudo original entre Racionalidade e Ontologia (e entre sentido do Ser e destinação ontológica) aprofundou estas reflexões e nos leva a afirmar que para pensar o Ser no horizonte hermenêutico de uma "nova" Racionalidade é imprescindível despi-lo das amarras da dimensão instrumental da Razão. Enquanto na Racionalidade que prepondera em nossas sociedades o aspecto instrumental é dominante, a Racionalidade Ambiental apoia-se mais em valores de uma nova cultura, construída coletivamente.

É por isso que o projeto de uma Racionalidade Ambiental é ancorado no saber Ambiental e, de acordo com algumas interpretações, se constitui em uma 
nova Ontologia, pois está profundamente comprometido com as formas de ser-no-mundo, reivindicando uma revisão de valores e um reposicionamento do Ser e da Razão.

Dando continuidade à discussão, encaminhamos para reflexão as teses que seguem, entendendo que tais fatores são essenciais para a construção de uma nova Racionalidade, algo que exige um compromisso especialmente dos educadores ambientais. Entendemos que, no horizonte da Racionalidade Ambiental, um novo lugar ao Ser será amanhado com base em valores que divergem daqueles promovidos pela Racionalidade Ocidental Moderna. Neste sentido, entendemos que o Ser da Racionalidade Ambiental se caracteriza pelas seguintes premissas:

I - É aquele que recupera o sentido da physis, no respeito e ressignificação da natureza: Na filosofia pré-socrática, a questão do Ser era tratada a partir do horizonte da physis, como elementos da natureza identificados como causas ordenadoras do universo. Observando os fenômenos naturais, os gregos antigos propuseram as primeiras questões filosóficas, desafiando o pensamento a pensar-se: daí o início do exercício filosófico. Na concepção pré-socrática, o Ser tinha sua unicidade afirmada frente à multiplicidade e diversidade. Os diferentes planos de realidade recolhiam em si uma unidade, ilustrada pelas alterações físico-químicas dos elementos, por exemplo. Neste horizonte filosófico, o Ser era a realidade e a realidade era o Ser, algo apreendido pelo pensamento a partir da experiência.

Já em Platão a realidade vem a ser cindida com a manifestação de uma dimensão suprafísica do Ser, que o coloca em dois planos: um fenomênico e um metafenomênico. A Teoria das Formas postula a Ideia como Ser por excelência e as filosofias posteriores refinam a dualidade platônica, separando corpo e alma, matéria e espírito, humanidade e natureza (algo levado ao extremo na Era Moderna).

A Racionalidade Ambiental propõe a ressignificação natureza, reorientando nosso pensamento em prol de um pertencimento há tanto esquecido em nome de ideais de dominação e progresso, como nos movimentos colonizatórios nas Américas e na África, por exemplo. Se na Racionalidade Ocidental a problematização filosófica está centrada na questão do sujeito (que conhece, nomeia e submete o outro-objeto-natureza), na perspectiva da Racionalidade Ambiental há uma ressignificação da vida e a proposta de "reavivar o Ser da complexidade", já que os efeitos da Racionalidade Instrumental se fizeram sentir na organicidade das sociedades, com a orientação eminentemente econômica no trato com os demais seres-do-mundo.

A Racionalidade Ambiental questiona a apropriação da natureza pelo capital, a hipereconomização do mundo e propõe, em contrapartida, a reapropriação social da natureza. Assim, a natureza deixa de ser reduzida a matéria- 
-prima e objeto de trabalho, mas volta a ser oikos, universo coabitado, lugar da coexistência, fonte de saber, palco da alteridade e potencial de vida. Segundo esta orientação, o Ser da Racionalidade Ambiental é aquele que recupera o sentido da physis, pelo respeito e ressignificação da natureza, como também pelo reconhecimento da complexidade do mundo, que vai além de toda construção conceitual: o Ser acontece na e com a natureza e o Outro.

II - É aquele que (re)significa o Sagrado: Esta tese refere-se às possibilidades de posicionarmo-nos frente ao que foge de nossa capacidade de explicação ou ao que chamamos de Sagrado. No Medievo, as questões ligadas ao Ser estavam em íntima relação com a ideia de Deus, o Ser necessário e doador de toda a perfeição.

Tanto Santo Agostinho como São Tomás de Aquino desenvolveram argumentações que procuraram conciliar a fé cristã e a filosofia helenística, com destaque para a destinação ontológica do Ser (humano) a partir dos preceitos da doutrina católica. Já num contexto posterior, com a expansão do protestantismo, o modelo de religião ajudou a construir as bases para o progresso material, com a ideia de sacrifício tanto em função do ideal religioso como em função do trabalho. Tal concepção ajudou a alicerçar as bases do capitalismo, como explicou Weber (2004). Os exageros da Racionalidade Instrumental e econômica forjaram um novo Deus (mercado), ao qual todos os processos sociais tendem a se converter.

Em contrapartida, compreendemos que no contexto da Racionalidade Ambiental constrói-se outra perspectiva em relação ao Sagrado. Na Modernidade foi promovida a obsolescência do conceito de Deus, em função da confiança no poder de uma Razão - objetivada na Ciência - que a tudo pode explicar. Intuímos que, a partir da construção de uma nova Racionalidade, as questões éticas podem nos impelir a uma redescoberta do Sagrado, seja ele identificado com uma "entidade" superior ou dissolvido nos milhares de rostos humanos e faces da realidade circundante.

A questão do Sagrado se faz presente quando incluímos em nossas relações a necessidade do Cuidar. Fala-se no cuidado da Terra, atormentados que estamos com a possibilidade de perder o equilíbrio necessário à manutenção da vida. Cuidar é preservar a vida, é respeitar as diferenças, tanto biológicas - já que não somos a única forma de vida que habita o planeta - quanto culturais. Nas palavras de Boff (2013),

Este modo de ser-no-mundo, na forma de cuidado, permite ao ser humano viver a experiência fundamental do valor, daquilo que tem importância e definitivamente conta. Não do valor utilitarista, só para seu uso, mas do valor intrínseco às coisas. A partir desse valor substantivo emerge a 
dimensão da alteridade, de respeito, de sacralidade, de reciprocidade e de complementariedade. Todos nos sentimos ligados e re-ligados uns com os outros, formando um todo orgânico único, diverso e sempre includente. Esse todo remete a um derradeiro Elo que tudo re-liga, sustenta e dinamiza. Irrompe como valor supremo que em tudo se vela e se revela. Esse Valor supremo tem o caráter de Mistério, no sentido de sempre se anunciar e ao mesmo tempo se recolher. Esse Mistério não mete medo, fascina e atrai como um sol. (BOFF, 2013, p. 110).

Nessa perspectiva, a ideia de Sagrado está para além de qualquer forma de representação divina ou institucionalização religiosa, superando tanto a teologia repressora de outrora quanto a sacralização do mercado. Nesta proposta, a ideia de Ser está na redescoberta do viver em comunhão.

III - Busca superar o paradigma da subjetividade pelo da intersubjetividade: Na Modernidade, a tematização filosófica versou com grande ênfase sobre a subjetividade, com o subjectum tomado como categoria de pensamento central. A ideia fundada por Descartes de sujeito como substância pensante atribuiu à reflexão metafísica moderna o caráter de Filosofia da Consciência.

O conceito de sujeito racional, como aquele que estabelece a nível mental a possibilidade de compreensão de si e do mundo exterior, forjou uma postura de oposição entre sujeito e objeto. Objetivar torna-se "prerrogativa da subjetividade": o eu é que nomeia, representa e (indo mais adiante na crítica, tal como fizeram os frankfurtianos) domina o que lhe é exterior.

Da diferenciação entre os outros seres da natureza (que simplesmente estão no mundo) e o homem (que está no mundo e pensa sua condição de existir, contrapondo-se a este mundo), o conceito de subjetividade refinou-se a ponto de supor a unidade entre o pensar e o Ser. Com a desteologização do mundo, tem lugar a noção de Homem Racional, que já não é mais visto como "dependente" de um criador ou divindade. Então, se o Eu é pura atividade reflexiva, conscientizar-se significa "trazer seu Ser ao pensamento". (BICCA, 1997, p. 187).

Em linhas muito gerais, no percurso da Filosofia da Consciência iniciado pelo cartesianismo, a necessidade de estabelecer a certeza e erradicar a dúvida coloca o sujeito como aquele que tem o domínio da sua consciência, que redunda em sua própria interioridade: cogito, ergo sum. Em Kant, a tarefa mais árdua da Razão é o conhecimento de si mesma, identificando seus próprios limites, daí a ideia de Razão Pura (como aquela que contém os princípios a priori para conhecer algo verdadeiramente).

Hegel considera que Kant desviou-se do foco primordial da Filosofia, que é a busca da verdade. Desenvolve a teoria de que a formação da consciência 
dá-se pela experiência associada à interpretação. Já Heidegger não considera que haja um "acesso privilegiado" da consciência a si mesma e é por isso que enxerga a subjetividade sob outra perspectiva: a de abertura. Ao fazer isto, o autor despoja o sujeito dos atributos classicamente a ele imputados e considera que a consciência é algo que nos sucede ou nos sobrevém, pois a existência é um evento histórico.

Nesse sentido, Heidegger coloca a questão da consciência sob outro viés de entendimento, já que a Filosofia da Consciência, ao privilegiar a dimensão racional, fechou-se em si mesma. Para Heidegger, o Ser acabou sendo esquecido ao ser ofuscado pela ciência e por meio da linguagem é que se daria a possibilidade de sua compreensão.

Na perspectiva da Racionalidade Ambiental, entende-se que o paradigma da subjetividade precisa ser reavaliado, havendo uma inclinação clara em favor da intersubjetividade, que redunda em protagonismo compartilhado e diálogo entre sujeitos. Habermas, ao apresentar a linguagem como elemento estruturador da relação do ser humano com a realidade, não apenas reforça sua dimensão social, mas lança as bases para a transição de uma Filosofia da Consciência para uma Filosofia da Linguagem.

Nesse sentido, as relações sujeito/objeto passam a ser relações entre sujeitos, pois com a saída da problemática do Eu, há um impulso a pensar a vida com o Outro. A oposição sujeito/objeto ou a afirmação do sujeito sobre o objeto fez com que os indivíduos perdessem sua identidade, sobretudo diante de um mundo hipereconomizado.

Por esta razão a superação do paradigma da subjetividade pelo da intersubjetividade é uma das premissas do Ser no contexto da Racionalidade Ambiental, visto que o círculo compreensivo para uma hermenêutica ambiental situa-se justamente no trânsito entre sujeito/objeto, universal/particular, subjetividade/ objetividade, sociedade/natureza e tantas outras dualidades constituídas pelo pensamento. A Racionalidade Ambiental pretende promover a abertura ao conhecimento e não a polarização de categorias, assim como busca reposicionar o sujeito que conhece e seu modo de conhecer.

IV - Compreende a necessidade de um reposicionamento dos saberes e da ciência: Na perspectiva da Racionalidade Ambiental, o conhecimento se dá já desde a pulsão por conhecer (LEFF, 2009), sendo construído a partir de vivências, de territorialidades, de histórias individuais e coletivas. O saber ambiental, ao buscar conhecer o que as ciências ignoram, incorpora aos saberes destas ciências princípios éticos e valores. A consciência de nossa incompletude e a impossibilidade de responder a todos os desafios do real convidam-nos a repensar os modelos de ciência da modernidade, ultrapassando o paradigma de mera justificação e validação da realidade externa. 
Em nosso entendimento, o saber ambiental implica a desconstrução de categorias conceituais inflexíveis, já que lida com a negação de um logos unificador. A unicidade de pensamento e método não condiz com a multiplicidade do mundo. Por ser um processo de construção social, o saber ambiental está intimamente relacionado com os modos de vida, diversos, plurais e potencialmente criativos. A crítica que se faz ao modo de fazer ciência na modernidade reside justamente na tentativa de unificação do pensamento, do apego à norma, ao modelo, ao sistema, em nome de uma "neutralidade". Para Leff (2006b),

[...] com sua obsessão pela objetividade dos dados, as variáveis e os fatos, a visão científica perde de vista a potencialidade do real, a fertilidade do devir, a abertura para a novidade, o campo do possível e a construção do futuro. Essa racionalidade nega a utopia como um projeto prospectivo gerador de mudanças sociais. (LEFF, 2006b, p. 84).

O desafio de reverter a crise ambiental passa pelo reconhecimento dos limites do entendimento da ciência, com a consideração de outras categorias de pensamento (e vida), tais como: alteridade, conhecimento sensível, sustentabilidade, diálogo de saberes e outras tantas que se voltam para a "re-erotização do mundo". (LEFF, 2009, p. 17).

A fragilidade da ciência moderna diante da complexidade do mundo reafirma a ideia de que a crise ecológica é uma crise da Razão, que não está sendo capaz de solucionar (ou evitar) problemas como a fome, as guerras, a violência, a pobreza extrema, a degradação ambiental e outros tantos que assombram as sociedades modernas.

A perda de referentes é um efeito contrário de um conhecimento que pretendeu ser único e totalizante. Os descaminhos da ciência acabaram por ignorar os mundos de vida, sujeitando comunidades e coisificando a natureza. Na concepção de uma Racionalidade Ambiental, a ciência transforma-se em um dos meios para apreender o mundo, não o único. O conhecimento é destituído de seu poder de manejo e controle da realidade, de seu caráter de justificação e comprovação teorética para assumir o papel de uma das possibilidades de busca de sustentabilidade para a vida.

\section{V - É aquele que busca vivenciar um engajamento ético e político:} Outro ponto fundamental a ser destacado é o horizonte ético e político da Racionalidade Ambiental. Ao estabelecer-se em territórios e histórias individuais e coletivas, a Racionalidade Ambiental está inscrita no mundo da vida, carregando consigo um significado alternativo à proposta da Racionalidade Ocidental Moderna. 
Na Modernidade muitos de nossos objetivos vêm sendo pautados pela lógica do Ter, como sinônimo de única (ou melhor) possibilidade de existência. Isto se dá a nível planetário, com a disputa de nações por monopólios industriais, por exemplo, e a nível microssocial, com a demanda crescente de consumo de bens, para assunção de um lugar social privilegiado. Comportamo-nos também como objetos. Se originariamente as relações Ser e Ter eram bem definidas, agora o sujeito também é objeto, na medida em que confunde-se com aquilo que adquire ou consome.

Os valores implicados neste tipo de atuação sobre o mundo (individualismo, desperdícios de toda ordem, descartabilidade de bens, indiferenças, consumismo, etc.) evitam que se desenvolva uma consciência social mais ampla, circunscritos que estamos em nossas demandas pessoais, que nos impedem de enxergar os excessos do pensamento utilitarista.

Para efetivação do projeto da Racionalidade Ambiental, é preciso que valores do ambiente sejam incorporados à ética individual e coletiva. No mesmo sentido, a socialização do acesso e a apropriação da natureza passam pela democratização dos processos produtivos e do poder político, aliados a uma legislação ambiental eficaz. (LEFF, 2006a).

Em nosso entendimento, o Ser da Racionalidade Ambiental é caracterizado pela premissa de engajamento ético e político, visto que repensa sua condição de ser-no-mundo, entendendo a necessidade de abertura ao diálogo; promove mudanças institucionais e jurídicas com vistas a atender a demandas sociais como distribuição das riquezas, diminuição das desigualdades sociais e da pobreza; elabora categorias para pensar o real a partir do reconhecimento das diferenças e da alteridade; desconstrói a visão utilitarista da natureza; e, enfim, é solidário com uma política do Ser (LEFF, 2009, p. 29), entendendo a realidade como construção social: daí o pressuposto de responsabilidade compartilhada.

VI - É aquele que compreende a necessidade de refuncionalizar o modelo socioeconômico atual: A Racionalidade Ambiental avalia que o processo econômico atual tem sido potencializador da entropia do planeta. A economia baseada nas regras do capital é incompatível com a ideia de sustentabilidade, visto que não promove a vida nem zela pela conservação das suas mais diferentes formas.

O objetivo do lucro, motor do modo de produção pelo qual temos optado, "dessubstancia o homem de seu ser para reduzi-lo a pura força de trabalho". (LEFF, 2006b, p. 33). Temos observado que os processos de exteriorização e desvalorização da natureza acabaram por convertê-la em mera matéria-prima ou fonte de energia que alimenta os processos produtivos. Para que ocorra uma modificação nos princípios produtivos, é necessário que se construam novos valores sociais, pois a transição para a sustentabilidade significa, na visão de Leff $(2009$, p. 1), "passar de uma economia entrópica para uma neguentrópica". 
A partir da teoria do valor-trabalho, Marx ancorou a argumentação do materialismo histórico, questionando as bases ideológicas do modo de produção capitalista. A relação entre trabalho abstrato e o tempo socialmente necessário para produzi-lo, bem como o paradoxo do progresso técnico (que aumenta a mais-valia, mas desvaloriza o capital e o trabalho), motiva a discussão a respeito da necessidade de refuncionalizar o modelo socioeconômico atual.

Leff avalia que nem mesmo o ecomarxismo conseguiu restaurar o princípio de valor. Se o capitalismo ajudou a romper com a unidade entre sociedade e natureza, com as regras do capital mediando as relações entre ambas, é preciso que se ultrapasse o modelo que instaurou a racionalização deste domínio da natureza.

De acordo com esta interpretação, a desconstrução da Racionalidade que enxerga o Ser como peça de um processo produtivo voltado ao lucro de poucos é passo indispensável para repensar o valor da natureza e do próprio sentido do Ser. A Racionalidade Ambiental sinaliza a possibilidade de restaurar a organicidade entre natureza e sociedade, transcendendo o predomínio do uso instrumental da razão ao compreender o ambiente como complexidade.

O projeto de construção de uma Racionalidade Ambiental envolve uma nova concepção de desenvolvimento e produtividade, com uma análise integrada das bases materiais das sociedades e com o fortalecimento de economias autogestionárias, por exemplo. Isto também envolve a superação do modelo de consumo que tem escravizado a natureza e as pessoas. Neste contexto, o Ser da Racionalidade Ambiental desvincula sua existência do conceito de Ter, para (re)significar a vida a partir de outros pressupostos.

\section{Conclusão}

A diversidade ontológica do real desafia-nos continuamente a interpretar e dar sentido ao existente. Embora não seja tarefa nova a busca pelo humano da humanidade, continuamos a perguntar: "O que significa este Ser do humano?"; "Quais as consequências disto na construção de relações e do nosso universo axiológico?"

A metafísica ocidental concedeu ao ser humano o maior estatuto ontológico entre os entes, o que ao nos entronizar como senhores da Razão e da natureza conduziu-nos a diferentes formas de relação com o Outro, fosse humano ou não humano.

A Racionalidade atrelada ao capitalismo moderno deu primazia à capacidade funcional dos sujeitos, reforçando uma dicotomia iniciada há tantos 
séculos entre homem (visto como sujeito da história) e meio (considerado objeto da ação do homem). Seja para aplacar as angústias existenciais primevas, para reforçar nossa posição de superioridade sobre os demais entes, para assegurar a propriedade, para expandir o capital, ou sob a égide de quaisquer outras intenções, a natureza foi sendo significada e tratada a partir da ótica da humanidade racional-civilizadora. Neste sentido, ousamos afirmar que a Racionalidade Ocidental não foi capaz de sustentar a harmonia humanidade-cosmos, mas, pelo contrário: ao supervalorizar a dimensão instrumental da Razão, transformou a maneira de vermos, significarmos e sermos no mundo.

Ao tratar o ambiente como mais um "objeto" (por mais variado, multiforme e plural que seja), acabamos por reafirmar os pressupostos de algumas epistemologias que disponibilizam tudo (o Outro, os objetos, o não eu) à manipulação do sujeito. Em nosso ponto de vista, tal concepção confirma que a crise ambiental é a crise da Racionalidade Moderna.

Em contrapartida, Leff nos apresenta a Racionalidade Ambiental como possibilidade de restauração dos princípios de "produtividade" e convivência, em sintonia com os propósitos de sustentabilidade. $\mathrm{O}$ autor alega que mesmo o socialismo utópico entende a vida a partir das bases da política econômica, repetindo o que já havia sido feito por outras correntes de pensamento como o racionalismo, o marxismo e a própria releitura social empreendida pela Teoria Crítica.

Ainda não fomos capazes de superar totalmente a Racionalidade Instrumental, que se manifesta, sobretudo, nos fenômenos que Habermas chamou de "colonização do mundo da vida". Como tratar da questão da equidade social, da democratização do acesso aos recursos, da valorização da vida, etc., sem gestar uma nova Racionalidade?

Nessa perspectiva, não se trata apenas de opor a Racionalidade Ambiental à Racionalidade Instrumental, mas compreender a primeira como possibilidade de pensar políticas alternativas de desenvolvimento, que sejam (o quanto possíveis) sustentáveis, equitativas e duradouras. Entende-se que tal projeto implica na concreção de uma utopia, já que se faz necessário ressignificar a ciência, os processos econômicos e tecnológicos, o ambiente e a própria vida.

Encaminhando a discussão para um término (por ora), salientamos que a implantação de uma nova Racionalidade implica em uma mudança profunda de valores que possam efetivamente se fazer presentes em nossas vidas. Cabe salientar que, mesmo considerando a importância do conhecimento objetivo das ciências, a Educação Ambiental se propõe a ir um pouco além, buscando conhecer o que estas ciências desconhecem, numa inquietude pelo não sabido. Isto, a nosso ver, constitui-se num movimento que é a gênese do desejo de conhecer e aprender. Tal desejo não finda em tentativas de encerrar o mundo 
em categorias conceituais rígidas e classificatórias, mas em compreender que nosso saber é limitado e finito, tal qual somos nós.

O saber ambiental não ignora a existência das relações de poder, ele "apenas" busca outra relação entre pensamento e Ser. O saber ambiental funda-se ainda no direito por manifestar a diferença e a incompletude e por promover, fundamentalmente, o encontro de identidades.

Sabemos que os progressos técnicos e tecnológicos, bem como o desenvolvimento das ciências, nem sempre se voltaram para um fim social mais amplo, aliados que estão com uma lógica de produtividade que aprisiona e limita os potenciais criativos dos grupos humanos. A Racionalidade Ambiental, ao questionar profundamente essas representações, pode constituir-se em uma alternativa para outros modelos de educabilidade, ampliando a concepção de saber, de aprendizagem, de ser-no-mundo.

Destarte, seria incoerente e inócuo almejar uma revolução ideológica e valorativa sem uma mudança nos paradigmas que orientam a educação. Uma pedagogia da complexidade ambiental precisaria voltar-se para a valorização dos saberes que partem de identidades plurais, observando o mundo como potencialidade de vida, desconstruindo os referenciais que associam a interação com o ambiente com a possibilidade de ganho econômico, ou a relação com os pares como fator de exclusão social.

A superação da relação sujeito-objeto também precisa ser estendida aos espaços educativos, favorecendo a cultura da colaboração, do cuidado e do respeito mútuo. Voltar o olhar ao entorno, às diferentes culturas e à história dos sujeitos não significa desprezar a construção das ciências mais tradicionais (inclusive das ciências e teorias da educação), mas ampliar as formas de conhecer e apreender o mundo, que, desde antes de qualquer intenção de educação formal, já vêm constituindo o Ser de cada um.

Ao compreender o Ser no saber, cria-se outra relação pedagógica, negando as certezas insustentáveis, as categorias conceituais inflexíveis que não têm estimulado mentalidades para gerar o inédito. A educação não pode se sujeitar a ser treinamento para, porque deve dar lugar também ao não saber, que é infinitamente maior do que efetivamente conhecemos. No contexto de uma educabilidade ambiental, as relações pedagógicas devem fugir do modelo de competitividade, dando lugar às potências do Ser.

A Educação Ambiental, sob nosso ponto de vista, foge das certezas do sujeito, da ciência, da norma, do modelo. A relação pedagógica que se estabelece é "deixar ser ao Ser" (LEFF, 2009), tendo como principal desafio reencantar a vida e desenvolver o sentido de responsabilidade partilhada.

Se entendermos que a Racionalidade Ambiental é um processo de construção social, faz todo sentido buscar, no campo da educação, a desconstrução do saber 
onicompreensivo e totalizante, integrando o conhecimento sensível e o racional, valorizando os saberes e restaurando a relação entre Ser, vida e conhecimento.

\section{REFERÊNCIAS}

BICCA, L. Racionalidade Moderna e Subjetividade. São Paulo: Edições Loyola, 1997. (Coleção Filosofia, n. 43).

BOFF, L. Saber Cuidar: ética do humano - compaixão pela Terra. 19. ed. Petrópolis: Vozes, 2013.

LEFF, E. Epistemologia Ambiental. São Paulo: Cortez Editora, 2006a.

LEFF, E. Racionalidade ambiental: a reapropriação social da natureza. Rio de Janeiro: Civilização Brasileira, 2006b.

LEFF, E. Discursos Sustentáveis. São Paulo: Cortez Editora, 2009.

MÜHL, E. H. Crítica à Racionalidade Instrumental: as contribuições de Adorno e Horkheimer. In: CENCI, A. (Org.). Ética, Racionalidade e Modernidade. Passo Fundo: EdiUPF, 1996.

PEREIRA, V. A. Ecologia Cosmocena: a redefinição do espaço humano no cosmos. Juiz de Fora: Garcia Edizioni, 2016.

PEREIRA, V. A. (Org.). Hermenêutica \& Educação Ambiental no contexto do Pensamento Pós-Metafísico. Juiz de Fora: Garcia Edizioni, 2016.

PEREIRA, V. A.; EICHENBERGER, J. C.; CLARO, L. C. A crise nos fundamentos da Educação Ambiental: motivações para um pensamento pós-metafísico. Revista Eletrônica do Mestrado em Educação Ambiental, v. 32, p. 177-205, 2015.

PORTO-GONÇALVES, C. W. Apresentação. In: LEFF, E. Racionalidade ambiental: a reapropriação social da natureza. Rio de Janeiro: Civilização Brasileira, 2006.

STEIL, C. A.; CARVALHO, I. C. de M. Epistemologias ecológicas: delimitando um conceito. Rio de Janeiro, 2014. Disponível em: <http://dx.doi.org/10.1590/S010493132014000100006>. Acesso em: 18 mar. 2016.

WEBER, M. A ética protestante e o espirito do capitalismo. São Paulo: Companhia das Letras, 2004.

Texto recebido em 21 de março de 2016.

Texto aprovado em 30 de abril de 2016. 